\title{
Methodology for the formation of university teacher readiness for the digitalization of the educational process
}

\author{
Andrey Vasilevich Leifa, Natalia Nikolaevna Dvoeriadkina, Tatiana Aleksandrovna \\ Yurieva, Natalia Anatolevna Chalkina
}

State University Amur, Ignatievskoe highway, 21, Blagoveshchensk, Russia

\begin{abstract}
The article discusses the methodology of forming the teacher's readiness to use the electronic educational environment by immersion technology. The relevance of the study is determined by the challenges of our time. During the pandemic, all educational institutions of the Russian Federation had to switch to distance learning for students. Which presupposes possession of digital technologies by all participants in the educational process. To bridge the «digital divide» in the student-teacher relationship, a methodology has been developed to improve the qualifications of the teaching staff, which allows them to organize their professional activities using digital technologies. The leading method of researching this problem was a pedagogical experiment conducted among teachers and students, which made it possible to identify a positive trend in the willingness of teachers to use the capabilities of the University's electronic information and educational environment based on the results of the proposed methodology. The article clarifies the structure of a teacher's readiness to use the electronic information and educational environment of an educational organization, substantiates the effectiveness of the methodology for the formation of readiness using immersion technology.
\end{abstract}

\section{Introduction}

Digitalization is confidently replacing the informatization and computerization of society in all spheres of its activity. The advantages and benefits of digitalization are discussed within the framework of various events $[1 ; 10 ; 11]$. The introduction of digitalization into all spheres of society forces the education system to change, sets new tasks for it.

The «digital divide» between generations is becoming evident. Today's schoolchildren and students were born in the age of modern information technologies, they use the Internet, cloud and digital technologies. It is safe to say that educators are digital savvy. Many teachers use digital technologies in teaching that make it easier to control the assimilation of the material and increase the productivity of classes [2,3]. Educational institutions have practically abandoned paper workflow, they have electronic diaries, electronic grade books and statements. However, it is not possible to completely abandon the classical teaching of subjects. 
The digitalization of the educational process in the conditions of a university is most naturally carried out through the electronic information and educational environment (EIEE).

In universities, in accordance with the federal state standard of the third generation, one of the system-wide requirements for the conditions for the implementation of any training program is the EIEE of a higher educational institution.

It is such a dynamically developing environment that is replenished with new resources, information and telecommunication technologies that can serve as the foundation for the digitalization of the educational process at a university. To date, neither in regulatory documents nor in scientific publications there is no unambiguous definition of the concept of EIEE. Based on the functions, subject to Art. 16 of the Federal Law «On Education in the Russian Federation» in the regulation of the Amur State University, EIEE is defined as «a set of information and telecommunication technologies, appropriate technological means, electronic information and educational resources necessary and sufficient for the organization of indirect (at a distance) interaction of students with pedagogical, educational - auxiliary, administrative and economic personnel, as well as among themselves» [4].

The functioning of the university EIEE is provided not only by material and technical, technological conditions and equipped by educational and methodological resources. The fundamental factor in the successful functioning of the EIEE is the willingness of teachers to work in this environment [5]. The definition of the concept of readiness of the teaching staff to work in this digital environment required the study of the terms «readiness», «readiness for professional activity».

Analysis of scientific works allows us to highlight various aspects of the study of «readiness»: from the standpoint of the theory of reflexes and attitudes (I. P. Pavlov, I. M. Sechenov); at the level of neurophysiological mechanisms of regulation and self-regulation (G. Sh. Gabdreeva, L. G. Dikaya); from the position of activity at the level of physiological and psychological mechanisms (V. G. Leontiev, N. A. Berstein). All these aspects consider the internal mechanisms of readiness for activity in general and define the term under study as the possession by a person of some complex quality that contributes to the performance of certain functions. The specification of readiness, depending on the type of activity, is considered from the standpoint of the conditions for its formation and manifestation in activity [6]. In domestic pedagogical studies, professional readiness is considered as a result of professional training (K. M.Durai-Novakova, V. B. Nikishina, V. A. Slastenin, etc.). In the works of these authors, it is noted that «readiness for professional activity» is manifested in the form of integral education, including the level of knowledge, skills and abilities in labor activity, as well as the formation of motives, needs and capabilities at the individual level and determines the attitude to activity and its effectiveness. Proceeding from this, the teacher's readiness to use the EIEE must be viewed through the prism of their professional activity.

The professional activity of a teacher for the undergraduate, specialist, and graduate programs is multifaceted. The labor functions of a teacher include research and innovation, and international cooperation, and the organization of psychological and pedagogical support of students [7]. But, a priori, the main ones are the organization of students' activities for the development of competencies, the creation of pedagogical conditions for the development of students, the creation of educational and methodological support [8], which are the components of the educational activity of the teacher.

The faculty and teaching staff understand that in order to remain competitive and raise the modern generation of specialists, it is necessary to create a digital educational environment and actively join it. To do this, teachers attend various master classes, online schools, refresher courses (full-time, part-time, distance), study terminology, create courses themselves and post them on various platforms. There are already a lot of materials that 
touch on various aspects of digital technologies and their use in educational activities. Each teacher, loaded with educational activities, has no opportunity to analyze all the available material. Therefore, self-learning is spotty and ineffective.

In this regard, a contradiction arose between the understanding of the need to digitalize the educational process, bridging the «digital divide» in the student-teacher relationship and the lack of an effective methodology for improving the qualifications of the teaching staff that allows them to organize their professional activities using digital technologies.

The outlined contradiction determined the research problem: what should be the methodology for the formation of the readiness of the teaching staff to use the EIEE.

Among the forms of advanced training that are used for teachers who carry out educational activities, most often there are distance learning, a personalized advanced training system, electronic, modular, project-based training, training in the format of an internship. Each of these forms has its own advantages, for example, distance learning allows you to organize interactive communication between participants in a distance course; when organizing a personalized system, an individual training route is built for each student; e-learning brings together all media resources; with modular training, each student can choose for themselves the modules they need, and with project-based training, the process of obtaining the necessary competencies is carried out in the process of the activity. All these forms of professional development require a separation of the teacher from the continuous educational process or the creation of additional workload for the teacher while completing the tasks necessary for taking advanced training courses.

Due to the need for mass professional development of teachers and at the same time the need to conduct a continuous educational process at the university, it was decided to develop a methodology for the formation of readiness based on the technology of «immersion in the subject». This technology is based on the well-known technology of concentrated teaching [9]. The essence of the technology «immersion in the subject» is that the organization of the educational process is realized through concentration on one subject of study for a certain time interval. At the same time, there is no distraction for the study of other disciplines. Mastering the same content is carried out in different forms of activity. According to numerous studies, this technology allows you to optimize the learning process by increasing the volume of the studied material, without increasing the time (G. I. Ibragimov, M. P. Shchetinin, A. A. Ostapenko).

The hypothesis of the study is that the successful digitalization of the educational process in a separate educational institution contributes to mass professional development courses organized with a direct immersion of students in the digital environment.

\section{Research methods}

The aim of the study is to develop and experimentally test the methodology for the formation of the readiness of the teaching staff of the university to conduct educational activities in the university's EIEE.

To achieve this goal, theoretical (the method of analyzing scientific sources, the experience of leading specialists; analysis of regulatory documents) and empirical (questionnaires; testing; the method of expert assessments; pedagogical experiment) methods, as well as methods of mathematical processing of the experimental results were used.

The study was carried out on the basis of the Federal State Budgetary Educational Institution of Higher Education «Amur State University» (AmSU). The study involved 250 university faculty members and 420 first- and third-year students. 
At the first, theoretical, stage of the research, the analysis of scientific, methodological literature on the problem being solved was carried out; determination of the scientific apparatus of the research; selection of research methods, stating the stage of the experiment.

The second, experimental, stage was devoted to clarifying the research hypothesis, generalizing theoretical provisions. At this stage, a methodology has been created for the formation of the readiness of the teaching staff of the university to conduct educational activities in the electronic information and educational environment of the university, a formative stage of the experiment has been carried out.

The third stage, generalizing, included the final stage of the experiment, mathematical processing, analysis of research results, summing up, formulating conclusions.

\section{Results}

Based on the activity-based nature of readiness, motivational, informational, and operational components were identified in its structure. The presence of these components in the structure of readiness for professional activity was noted by all key works studying vocational training.

The information component characterizes the body of knowledge about the elements, functions of the EIEE, about the methods of organizing educational activities through the elements. To assess the formation of the information component, indicators were determined that correlate with the didactic units of the course content. Direct assessment was carried out using testing in the Moodle system. Thus, the mass scale of test results and the automation of their processing were ensured. The operational component characterizes skills, mastery of execution technology. To assess the formation of this component in the electronic information and educational environment of the university through the student's personal account, a survey of students was carried out. The questionnaire included questions that allow assessing the ability of teachers in various subjects to use the capabilities of EIEE in their activities when teaching students. We analyzed the statistics of maintaining electronic journals, the use of independently created and publicly available courses. The third - motivational component (needs) characterizes the awareness of the role of digitalization in the development of professional qualities, the belief system, the motives of teachers, the manifestation of interest in improving knowledge and skills in the use of EIEE in educational activities. To assess the formation of this component of readiness, we measured the manifestation of interest in the possibilities of the EIEE and the digitalization of one's educational process, the need to consciously use the electronic information and educational environment in one's professional activities, and the awareness of the importance of digitalization for the educational process.

At the ascertaining stage of the experiment, a survey of the entire faculty of the university was carried out in order to find out how the teachers relate to the use of EIEE in their professional activities (Fig. 1). The practice of contact work of teachers with students in the electronic information and educational environment of the university was also studied. Due to the fact that each teacher must fully possess the skills of working in the electronic information and educational environment and involve his students in its use, a complete survey of the entire teaching staff and students was carried out. 


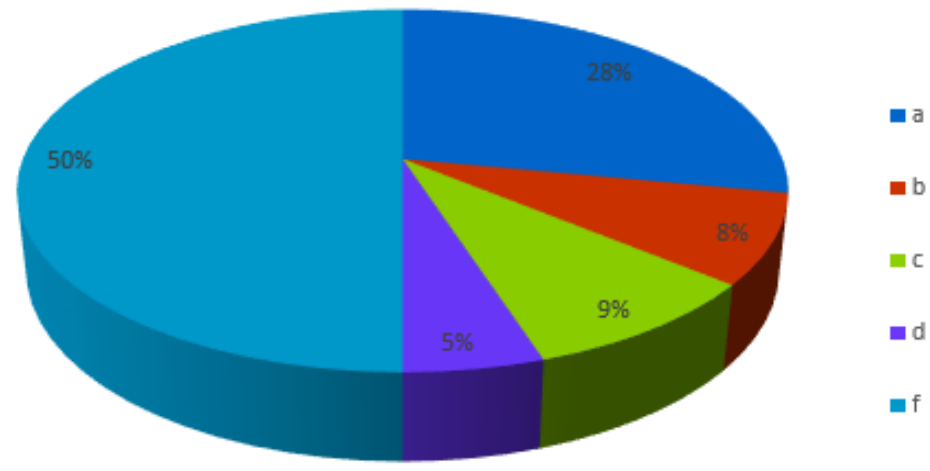

Fig. 1. The attitude of teachers to the use of EIEE in organizing contact work (a - I always use EIEE in my work, b - I use EIEE in my work quite often, c - sometimes I use EIEE for work, d - I use EIEE very rarely, f - I don't use EIEE for work)

With the help of a continuous questionnaire survey of university teachers, it turned out that at the beginning of the experiment, only $28 \%$ of the respondents confidently used the means of EIEE, knew the conceptual apparatus, the content of the structural components and the principles of operation of this environment; slightly more than $50 \%$ of teachers were negatively disposed to use the EIEE to organize their training sessions.

In addition, using a questionnaire survey of students, it was found that third-year students, in general, treated the electronic information educational environment of the university only as a library resource and used it only to search for the textbooks and teaching aids they needed. The first-year students did not understand how communication and learning could be carried out within the electronic informational educational environment of the university. All students noted that teachers could not help them fully adapt to the electronic information educational environment of the university and did not often use it when organizing contact work (Fig. 2).

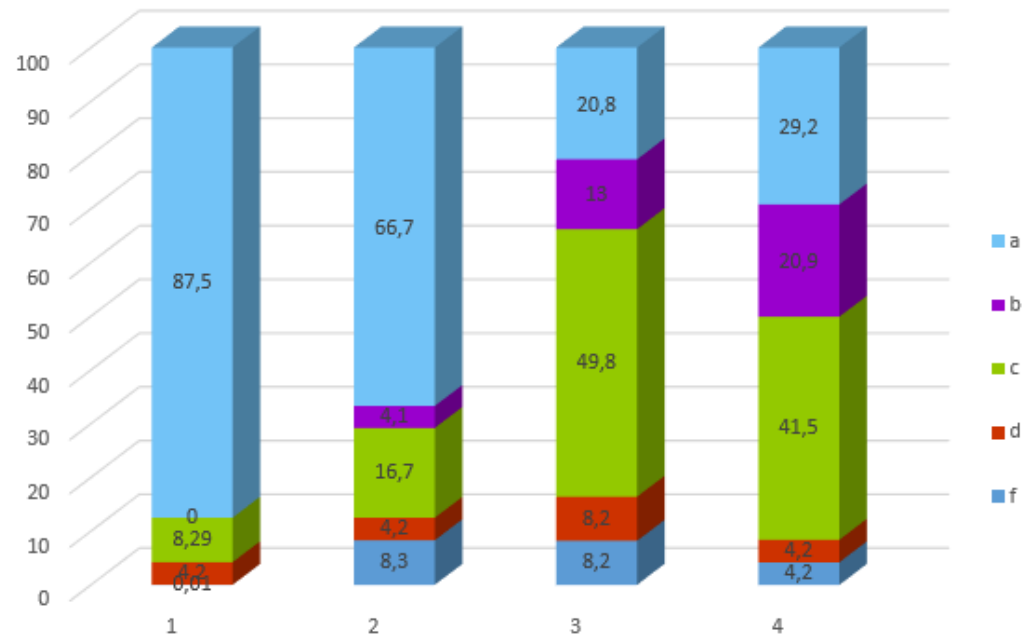

Fig. 2. Students' readiness to use EIEE (a - I don't use it, I don't know what it is b - I use EIEE for consultations, c - I use EIEE to search for textbooks and teaching aids, d - I use EIEE for teaching, f I use EIEE for communication) 
Analysis of the results of the first stage of the experimental work showed that it is necessary to help teachers effectively use the electronic information and educational environment with the help of refresher courses.

At the second stage of the experiment, the leadership of the university created a working group from among the leading teachers of the university, which developed a program of advanced training courses «Use and support of EIEE and information and communication technologies in an educational organization» (https://aem.amursu.ru/enrol/index.php?id=17). The transformation of the immersion technology for conducting refresher courses was that the information received by the teacher was applied immediately in the course of the real educational process conducted by this teacher with the students. All faculty members of the university need to improve their qualifications in these courses.

All subjects were randomly divided into two groups: control and experimental. The randomness of the division ensured the homogeneity of the groups in all indicators of the readiness components (Fig. 3).

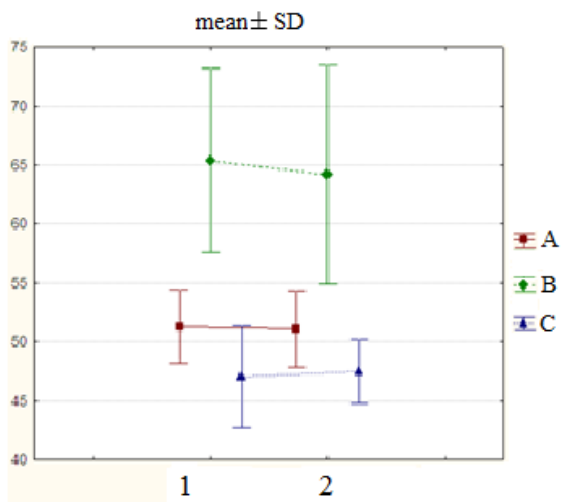

Fig. 3. Homogeneity of the control (1) and experimental (2) groups in terms of readiness components (A - motivational component; B - information component, C - operational component)

In the control group, teaching advanced training courses was carried out in a classical way. The trainees were trained in lectures and practical classes, students were not involved in this educational process.

In the experimental group, the qualifications of teachers were carried out using the technology of immersion in electronic information and educational environment. The trainees had to not only improve their qualifications in the courses, but also carry out the educational process in their subject within this environment. Thus, students also found themselves immersed in an electronic information educational environment.

In the experimental group, the courses were conducted in distance and full-time forms. The distance learning part of the course was on Moodle. Each teacher, through messages to their personal account, received a login and password to enroll in the course. The timing of the course was chosen by the teacher individually, taking into account their workload in the learning process. Each attendee became a participant in the university's EIEE. During this advanced training, teachers not only trained themselves in this environment, but they also trained students in their classes in this environment when completing course assignments.

The distance part of the course contained material that explained the main provisions, provided links to regulations, presented the experience of other universities in the electronic information and educational environment. The material was presented in various formats: 
video lectures, presentations, text documents, podcasts. Each attendee could choose a training format that was convenient for them.

Teachers actively used their personal account on a daily basis not only to fill out an electronic journal, but also to communicate with students, colleagues, and view university news. In the personal account, each faculty member began to regularly update their portfolio, making personal accounts a dynamic element of the university's EIEE.

In addition, many teachers, in the process of completing assignments during training in advanced training courses, have created fragments of online courses for their subjects and continue to work on them at the present time. Created courses are hosted in Moodle. Students enroll in courses and use them to gain a deeper understanding of the studied material.

Upon completion of refresher courses "Use and support of EIEE and information and communication technologies in an educational organization" all teachers of the university conducted the third final stage of the experiment. At this stage, repeated measurement of the indicators of the components of teachers' readiness (Fig. 4) and statistical processing of the results of the experiment were carried out.

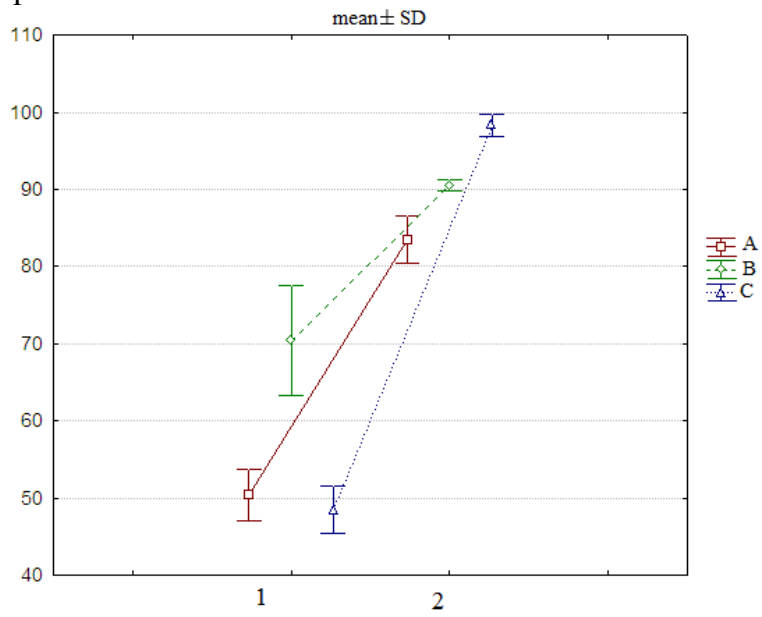

Fig. 4. Distribution of the average values of readiness indicators after the experiment in the control (1) and experimental (2) groups (A - motivational component; B - information component, C operational component)

Statistical processing of the obtained data was carried out using the StatSoft STATISTICA package. To determine the difference between the indicators of the control and experimental groups we used Student's parametric test in the case when the indicators obeyed the normal distribution law, and nonparametric Mann-Whitney test in the case when the distribution was statistically significantly different from the normal one. For the statistical analysis of shifts before and after the experiment separately in the control and experimental groups, the Student's test for dependent samples and normal distribution and Wilcoxon's test for dependent samples and distribution that did not obey the normal distribution law were used.

Assessment of the significance of differences after the pedagogical experiment

\begin{tabular}{|l|l|l|l|}
\hline \multirow{2}{*}{ Readiness component } & Group & Significance level \\
\cline { 2 - 3 } & Control & Experimental & \\
\hline Motivational & $50,3 \pm 0,25$ & $83,5 \pm 0,21$ & $\mathrm{p}=0,00035$ \\
\hline Information & $70,4 \pm 2,85$ & $90,5 \pm 0,03$ & $\mathrm{p}=0,0005$ \\
\hline Operational & $48,5 \pm 1,21$ & $98,3 \pm 0,55$ & $\mathrm{p}=0,00001$ \\
\hline
\end{tabular}


Analysis of the results showed that the number of teachers in the control group willing to constantly use the electronic information and educational environment of the university compared to the beginning of the experiment has not statistically changed. While in the experimental group there was a significant shift towards an increase in the number of teachers who are ready to constantly use the capabilities of the University's EIEE, 97\% of the teachers in the experimental group began to consider the electronic information and educational environment as their comfort zone. In addition, in the experimental group, there was no more negative attitude towards the use of EIEE for organizing their training sessions among all teachers, and in the control group this indicator did not change.

\section{Conclusions}

After completing advanced training courses «Use and support of EIEE and information and communication technologies in an educational organization» using the methodology of formation of readiness by immersion technology in the environment, teachers began to consider this environment as their comfort zone. They are comfortable working in it. Therefore, we can assume that the hypothesis has been confirmed that mass refresher courses organized with the direct immersion of students in the digital environment contribute to the successful digitalization of the educational process.

\section{References}

1. V. G. Khalin, G. V. Chernova, Management Consulting, 10(118), 46 (2018)

2. R. M. Safuanov, M. Yu. Lehmus, E. A. Kolganov, Bulletin of Ufa State Petroleum Technological University. Science, education, economics, Series: Economics, 2(28), 108 (2019)

3. N. P. Petrova, G. A. Bondareva, World of science, culture, education, 5(78), 353 (2019)

4. AMSU personal account, https://cabinet.amursu.ru/

5. S. S. Filippov, N. G. Zakrevskaya, P. G. Bordovskiy, L. A. Zavarukhina, Scientific notes of the University named after P. F. Lesgaft, 8(138), 234 (2016)

6. A. D. Plutenko, A. V. Leifa, V. V. Eremina, T. V. Khaletskaya, Bulletin of Tomsk State University, 439, 178 (2019)

7. T. G. Ozernikova, D. A. Elovenko, Baikal Research Journal, 8(2), 32 (2017)

8. Professional standard «Teacher of vocational training, vocational education and additional vocational education», http://fgosvo.ru/

9. E. K. Gitman, Bulletin of the Perm State Humanitarian Pedagogical University, Psychological and pedagogical sciences, 2, 6 (2015)

10. A. D. Plutenko, B. A. Karev, A. V. Leifa, Science and school, 5, 44 (2015)

11. N. A. Chalkina, T. A. Yurieva, In the collection: Practical Pedagogy and Psychology: Methods and Technologies, a collection of articles from the International Scientific and Practical Conference, 150 (2016)

12. A. V. Leifa, N. N. Dvoeriadkina, T. A. Yurieva, Environment Journal of complementary medicine research, 11(2) (2020) 
13. N. A. Chalkina, Proceedings of the 2020 IEEE International Conference "Quality Management, Transport and Information Security, Information Technologies", IT and QM and IS 2020, Yaroslavl, 9322924, 593 (2020) 